\title{
Serve routine preparation: Benefits of a combination of imagery, ball bounce and breathing on performance
}

\section{Laurent Dominique a \& Nicolas Robin ${ }^{\text {a }}$}

${ }^{a}$ Université des Antilles, Pointe-à-Pitre, Guadeloupe.

\section{ABSTRACT}

The objective of this study was to test the benefit of consistent training in developing and using individualized service preparation routines composed in particular of motor imagery, ball bounce and breathing in order to provide practical recommendations to coaches. The results show an improvement in the percentage of first serve and effectiveness in experienced players.

\author{
Key words: service, routine, \\ mental imagery, tennis. \\ Received: 1 July 2020 \\ Accepted: 20 September 2020 \\ Corresponding author: \\ Nicolas Robin, Laboratoire \\ ACTES, UFR STAPS, Campus \\ Fouillole, Pointe-à-Pitre Cedex, \\ Guadeloupe. Email: \\ robin.nicolas@hotmail.fr
}

\section{INTRODUCTION}

Motor Imagery (MI) is a conscious process that involves mental stimulation of a motor action (Robin et al., 2007). It is a technique mostly used by coaches, in addition to actual practice, to improve the performance of tennis players (Guillot, Desliens, Rouyer, \& Rogoswski, 2013). MI is done on the action that base on the mental representations that build from the body with sensory modalities or the environment such as visual images (Dana \& Gozalzadeh, 2017; Robin \& Joblet, 2018). As the MI allows to regulate players attention, it is frequently integrated into their performance routines (Le Scanff, 1999) especially in order to focus their attention on other elements than the technique of the stroke that they will perform and allow them to initiate their movement under standardised conditions as possible (Jackson \& Baker, 2001). For example, before serving, it is common to see professional players taking a deep breath in and out or bouncing the ball a number of times as shown in the photo.

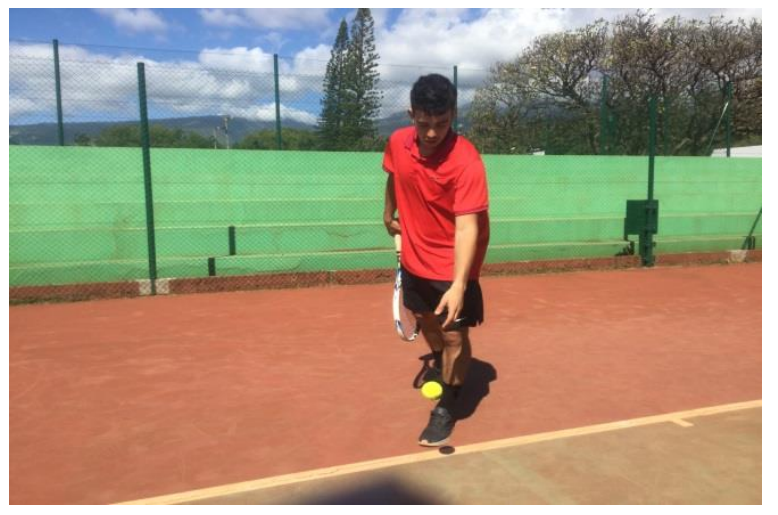

Similarly, some players do $\mathrm{Ml}$ before serving because this technique has shown positive effects on performance (Desliens, Guillot, \& Rogoski, 2011; Fekih et al., 2020; Guillot, Genevois, Desliens, Saieb, \& Rogowski, 2012; Mamassis, 2005). For example, Guillot et al. (2013) showed that the combination of physical practice and $\mathrm{MI}$, with focus on the ball trajectory, had improved speed and accuracy of service. All previously mentioned elements lead us to think that it would be beneficial, for advance players, to create, stabilize and based particularly in MI use serve routines on an external focus. The purpose of this experiment was to assess the influence of a routine that prepare a serve that made up with of deep breathing, a number of personalized ball bounces and MI.

\section{METHOD}

Twenty two tennis players ( $M=16.9$ years) training at the HDN Academy in Nîmes voluntarily participated in this study. They were divided into 2 groups: control and imaging routine.

\section{PROCEDURE}

During 5 months, the players carried out 20 sessions of 1.5 hours during which, after the warm-up, they had to serve 25 times in match condition. The imaging routine group was instructed, 
before each first serve, to use a routine made of breath in then a deep breath out, then a certain number of ball bounces at the same time as the MI which was to visualize the trajectory and the zone bounce of the ball. The control group did not receive any specific instructions.

During the first session, players carried out the test 1:25 first serve in match condition. The percentage of success, the speed of the balls (with a radar) and the efficiency (scores ranging from " 0 " ball in the net or fault to " 5 " ace) of each serve were recorded by 2 state certified coaches. At the end of the 20 sessions, the players took test 2 identical to test 1 .

\section{RESULTS}

The statistical analysis performed on the speed of the balls did not show a significant difference between the services of the control group (average $=149 \mathrm{~km} / \mathrm{h}$ ) and those of the routine imagery group (average $=155 \mathrm{~km} / \mathrm{h}$ ) at the test. 2 .

On the other hand, the results show that the players in the routine imagery group improved (between test 1 and test 2) their first ball pass percentage by $15 \%$ while that of the players in the control group remained stable. In addition, the players who used the routine serve preparation (routine imaging group) obtained a higher success rate at first balls than those who did not use routine (control group) during test 2 (see figure below).

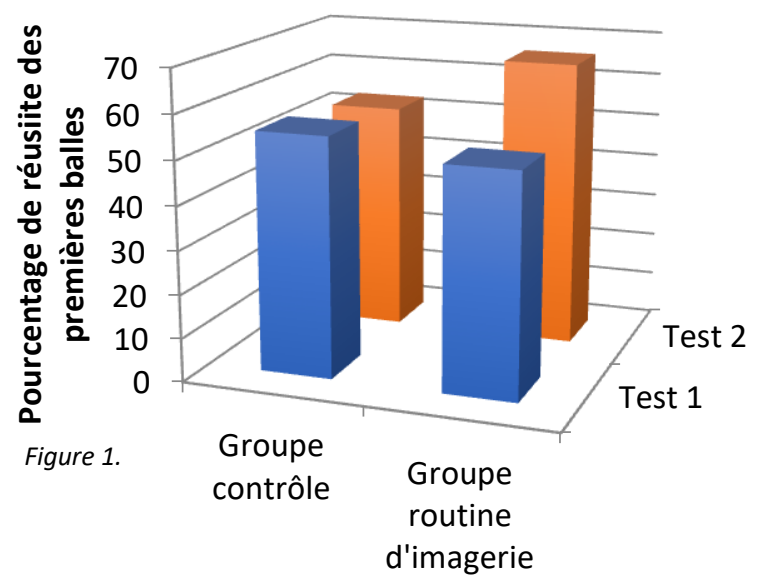

Finally, the players in the imagery group improved the efficiency of their first serve balls between test 1 and test 2, and served more effectively than those in the control group in test 2 (see figure below).

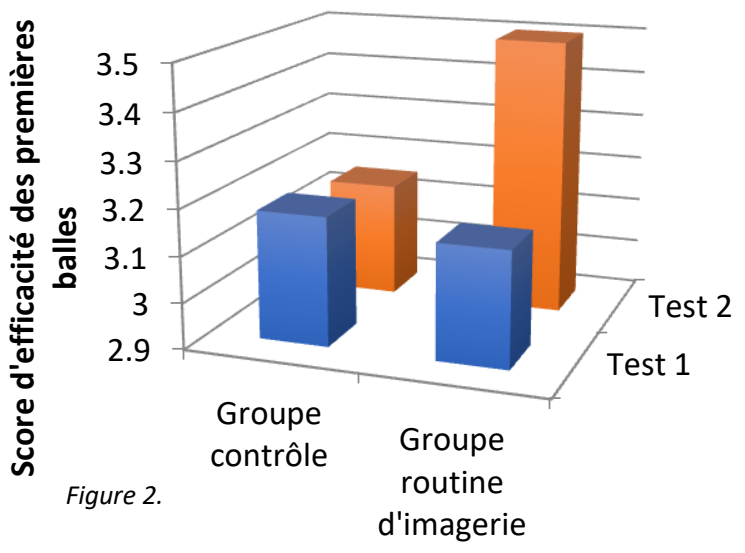

\section{DISCUSSION}

This experiment was carried out to assess the effects of the serve routine preparation, repeated and stabilized in training in match conditions, combining breathing, individualized ball bounce and $\mathrm{MI}$ focused on the trajectory of the ball and the target area to reach. The results obtained show a significant improvement in the percentage and efficiency of the first serve in players who have benefited from an imaging routine. These results confirm those of previous studies which have shown the beneficial effect, in tennis, of combining $\mathrm{Ml}$ with real practice both by advance players and beginner (Coelho et al., 2007; Guillot et al., 2012; Fekih et al., 2020; Robin et al., 2007; Robin et al., 2019). In addition, our results are in line with the work of Guillot et al. (2013) who showed the positive effects of $\mathrm{MI}$, with external focus, i.e. the player is asked to visualize the trajectory of the ball that he want to serve and the target he wish to reach. We recommend coaches rather to ask players to focus on the effects and consequences of their serve than technical stroke (Wulf et al., 2002). Finally, this experience underlines the benefit of integrating deep breathing into the MI Serve routine preparation, allowing the player not to focus on negative thoughts or parasitic images (Clark, Luckett, \& Kirkendall, 2010; Jackson \& Baker, 2001). On the other hand, it seems that the use of the bounce of the ball, whose control is automated, favors the use of external attentional focus during MI (Dominique, 2005).

\section{CONCLUSION}

The results of this field study, carried out under match conditions, show that the use of the serve routine preparation with breathing, individualized ball bounce and $\mathrm{MI}$ improves efficiency and the percentage of the first ball success. We recommend that coaches develop and generalize the use of the first serve routine preparation.

\section{REFERENCES}

Coelho, R. W., De Campos, W., Da Silva, S. G., Okazaki, F. H., \& Keller, B. (2007). Imagery intervention in open and closed tennis motor skill performance. Perceptual Motor Skills, 105, 458-468, https://doi.org/10.2466/pms.105.2.458-468

Dana, A., \& Gozalzadeh, E. (2017). Internal and External Imagery Effects on Tennis Skills Among Novices. Perceptual and Motor Skills, 124(5), 1022-1043, https://doi.org/10.1177/0031512517719611

Desliens, S., Guillot, A., \& Rogowski, I. (2011). Motor imagery and serving precision: A case study. ITF Coaching and Sport Science Review 55, 9 10.

Dominique, L. (2005). La préparation mentale : approche théorique et pratique en tennis. Thèse de doctorat, Université de Paris $\mathrm{XI}$, Paris.

Fekih, S., Zguira, M. S., Koubaa, A., Masmoudi, L., Bragazzi, N. L., \& Jarraya M. (2020). Effects of Motor Mental Imagery Training on Tennis Service Performance during the Ramadan Fasting: a Randomized, Controlled Trial. Nutrients, 12(4), E1035, https://doi.org/10.3390/nu12041035

Guillot, A., Genevois, C., Desliens, S., Saieb, S., \& Rogowski, I. (2012). Motor imagery and 'placebo-racket effects' in tennis serve performance. Psychology of Sport and Exercise 13, 533-540, https://doi.org/10.1016/j.psychsport.2012.03.002

Guillot, A., Desliens, S., Rouyer, C., \& Rogowski, I. (2013). Motor imagery and tennis serve performance: The external focus efficacy. Journal of Sports Science and Medicine, 12(2), 332-338.

Jackson, R.C. \& Baker, J.S. (2001). Routines, rituals, and rugby: Case study of 
a world class goal kicker. Human Kinetics Publishers, Inc, https://doi.org/10.1123/tsp.15.1.48

Le Scanff, C. (1999). Les routines de performance, dans Le Scanff (C.),

Famose (J.-P.), Gestion du stress : entraînement et compétition, Paris, EPS, p. 54-60.

Mamassis, G. (2005). Improving serving speed in young tennis players. ITF Coaching and Sport Science Review, 35, 3-4.

Robin, N., Dominique, L., Toussaint, L., Blandin, Y., Guillot, A., \& Le Her, M. (2007). Effects of motor imagery training on service return accuracy in tennis: The role of imagery ability. International Journal of Sport and Exercise Psychology, 2, 177-188, https://doi.org/10.1080/1612197X.2007.9671818

Robin, N., \& Joblet, E. (2018). L'imagerie mentale en EPS et si on essayait ? Enseigner l'EPS, 275, 5-9.

Robin, N., Toussaint, L., Charles-Charlery, C., \& Coudevylle, G.R. (2019). Free Throw Performance in Intermediate Basketball Players: The Effect of Dynamic Motor Imagery with and without a Video of a Model. Learning and Motivation, 68 https://doi.org/10.1016/j.Imot.2019.101595

Wulf, G., McConnel, N., Gärtner M., \& Schwarz, A. (2002). Enhancing the learning of sport skills through external-focus feedback. Journal of Motor Behavior, 34, 171-182,

https://doi.org/10.1080/00222890209601939

RECOMMENDED ITF TENNIS ACADEMY CONTENT (CLICK BELOW)

\section{ITF Academy}

Copyright (c) 2020 Laurent Dominique \& Nicolas Robin

\section{(ㄷ) 8}

This text is under a Creative Commons BY 4.0 license

You are free to Share - copy and redistribute the material in any medium or format - and Adapt the content - remix, transform, and build upon the material for any purpose, even commercially under the following terms:

Attribution: You must give appropriate credit, provide a link to the license, and indicate if changes were made. You may do so in any reasonable manner, but not in any way that suggests the licensor endorses you or your use.

CCBY4.0 license terms summary CCBY4.0license terms 